\title{
Cognitive Impairments in Children with Down Syndrome
}

\author{
Wajeeha Abdul Ahad ${ }^{1 *} \quad$ Fazaila Ehsan $^{2} \quad$ Noreen Fatima $^{3} \quad$ Faiza Yousaf $^{4}$ \\ Rabia Qamar ${ }^{5} \quad$ Ambreen Sadaf $^{6} \quad$ Sehar Ashraf $^{7}$ \\ Department of Health Professional Technologies, University of Lahore, PO box 54000, Lahore, Pakistan
}

\begin{abstract}
This study is designed to determine the cognitive impairments in individuals with Down syndrome. This study was conducted in September to November 2014. Sample of 30 patients was taken by using purposive sampling technique within three months. Observational and Cross-sectional study design was used. This was a hospitalbased study in which patients with Down's syndrome between the age range of 5-18 and both genders were included. A structured questionnaire was developed that was based on Piaget's theory of cognitive development to assess the cognitive abilities by assessing tasks related to developmental ages. Out of those 30 patients $15(50 \%)$ were male and $15(50 \%)$ were females. Most of the patients were found in age range of 5-10 years according to frequency $16(53.3 \%)$ followed by $10(33.3 \%)$ patients in $10-15$ years and $4(13.3 \%)$ in $15-20$ years. The preoperational stage of cognitive development showed that the girls were more impaired. Pretend-play (boys $(50 \%)$, girls $(46.7 \%)$ ), Centration(boys $(40 . \%)$, girls $(33.3 \%)$ and irreversibility boys $(50 \%)$ girls $(40 . \%)$ are the aspects in which boys were tending to show better than boys. In concrete operational stage and in formal operational stage both genders were tending to show equal impairments in their cognitive aspects. In the children with Down syndrome it is observed that there is high frequency of cognitive impairment and girls are more cognitively impaired than boys. While the tasks which require more accuracy and intelligence such as reasoning, meta-cognition, inductive and deductive reasoning are rarely present in both genders.
\end{abstract}

Keywords: Down syndrome, pre-operational, concrete-operational and formal-operational.

DOI: $10.7176 / \mathrm{JHMN} / 71-12$

Publication date: February $29^{\text {th }} 2020$

\section{Introduction}

Down syndrome is an inherited autosomal aberration in which there is an extra chromosome, 21 , in about $95 \%$ of patients. Other genetic variation includes translocations in which chromosome 21 has attached to another chromosome, such as number 14, and mosaics in which the person has two cell lines, one normal and other with 47 chromosomes, also called Down syndrome or mongolism (an old term). (1) Down syndrome is a most common chromosomal disorder. Every year, about 6,000 baby births presents with Down syndrome, which is about 1 in every 700 babies born.(2) . In 94\% cases trisomy 21 is underlying genetic defect. Translocations (3.3\%) and mosaicism (2.4\%) are also underlying causes. $75 \%$ translocations are de novo errors. In order to understand the underlying genetic defects, we must understand the basic genetics. In all reproduction cases genes are passed to the children from both parents. Chromosomes carry these genes. During the development of baby's cell, it is supposed that each cell receives 23 pairs of chromosomes half chromosomes come from mother and half from father. One chromosome does not separate properly in Down syndrome children. So instead of two there are three copies of chromosomes. In the brain and physical development of Down syndrome child this extra chromosome causes problems.(3). Etiology of this syndrome includes viral infections, auto-immune problems, genetic predispositions, diabetic mothers and mothers with one ovary. There are 3 types of Down syndrome: Trisomy 21: is the commonest type of Down syndrome. In this there is an extra copy of chromosome 21 in each cell. Mosaicism: In this type copy of extra chromosome is found only in some cells not all over the body. Individuals with this type tend to have fewer symptoms. Translocations: children have only 1 extra part of chromosome 21 these individuals have 46 chromosomes however an extra piece of chromosome 21 is attached with one of them. Risk of giving birth to a Down syndrome child is greater in certain parents: women greater than 35 years of age and males greater than 50 years of age, people with a family history of Down's syndrome, people who carry the genetic translocation there are no signs whether a child will have Down syndrome or not during pregnancy. Babies with Down syndrome usually have certain clinical features, including: small head, flat facial features, short neck, bulging tongue, eyes that slant upward, oddly shaped ears, poor muscle tone. Down syndrome infant at the time of birth are normal in size. However, the rate of growth is slow as compared to a normal child. Usually degree of mental retardation is mild to moderate. Mental development delays may affect the child's: impulsive behavior, judgment, attention span and learning capabilities. This medical complication is caused by the abnormal number of chromosomes either the number of chromosomes become more than normal, or they can become less than normal in this condition. Defects which cause this syndrome may include: congenital heart defects, hearing loss , poor vision, cataracts (clouded eyes), hip problems, such as dislocations, leukemia, chronic constipation, sleep apnea (interrupted breathing during sleep), dementia (thought and memory problems), hypothyroidism (low thyroid function), obesity, late tooth growth, causing problems with chewing Cognition can be defined as "all the mental activities associated 
with thinking, remembering, perception, attention span, learning and communication"(4) Cognition deals with the understanding of a person.. It deals with the abilities, skills or processes that are part of every human action. Cognitive abilities are skills based on the use of brain. The cognitive abilities deal with learning and understanding rather than with actual knowledge these are the abilities which allow perception. (5)

Cognitive abilities. (5)

\begin{tabular}{|l|l|}
\hline $\begin{array}{l}\text { Cognitive Ability/Brain } \\
\text { Function }\end{array}$ & Skills involved \\
\hline Perception & Recognition and interpretation of sensory stimuli (smell, touch, hearing, etc.) \\
\hline Attention & Ability to concentrate on a particular object, action, or thought. \\
\hline Memory & $\begin{array}{l}\text { Ability to remember, Short-term/ working memory (limited storage). } \\
\text { Long-term memory (unlimited storage). }\end{array}$ \\
\hline Motor & $\begin{array}{l}\text { Ability to mobilize our muscles and } \\
\text { Ability to move objects. }\end{array}$ \\
\hline Language & $\begin{array}{l}\text { Skills allowing us to translate sounds into words and generate verbal output. The } \\
\text { ability to generate verbal response }\end{array}$ \\
\hline $\begin{array}{l}\text { Visual and Spatial } \\
\text { Processing }\end{array}$ & $\begin{array}{l}\text { Ability to process incoming visual stimuli. Ability to understand spatial relation- } \\
\text { ship between objects. Ability to visualize images and scenarios. }\end{array}$ \\
\hline
\end{tabular}

Cognitive deficit is a term that describes defects in intellectual functioning (e.g., mental retardation). Sometimes it may be used to describe specific defects of cognitive abilities (e.g., certain learning disabilities such as dyslexia). In contrast, terms such as learning disability describe specific defects of certain processes that may have little to do with overall cognitive functioning.(6). The purpose of study on this topic is to determine impairment of cognitive skills in individuals suffering from Down syndrome. This study is done with respect to gender and cognitive skills training is done to help those individuals. Objectives of this study are as follows:

1. Determination of cognitive impairment in males and females with Down syndrome.

2. To assess cognitive skills of patients so that their level of impairment can be assed

\subsection{Methodology}

This study was carried at Department of Developmental Pediatric, CH\& ICH Lahore \& Department of Occupational Therapy, Rising Sun, Lahore. It is an Observational Cross-sectional Study. Questionnaire based on Piaget's theory of cognitive development was used for data collection. Data was collected in duration of three months. 30 patients were selected for the study (15 Males \& 15 Females). Nonrandom purposive sampling technique was used. Sample selection criteria include the inclusion criteria (Individuals with age range from 5 years to 18 years and Individuals with Down syndrome). And exclusion criteria include All other patients who are not fulfilling the above-mentioned criteria are excluded. All the patients fulfilling the inclusion criteria were evaluated by Occupational therapist, Pediatrician and Psychologist for the cognitive impairment during this period. After taking permission from authority of the relative institute and department we approach patient's care givers and teachers. Appropriate statistical data analysis technique by using SPSS (statistical package for social science) is applied. Age ranges and gender represented by using Pie Chart and cognitive impairment represented by using Bar Charts.

1.1.1 Results

This study had been conducted in Developmental Pediatrics department of Children Hospital, Institute of Child Health Lahore and Rising Sun Institute for Special Children. The data had been collected using questionnaire in the duration of 3 months from July, 2014 to September, 2014. The data has been analyzed through SPSS 20: That is as follows, Sample of 30 patients had taken who lie in age range of 5-18 years with diagnosis of Down syndrome have been selected. Out of those 30 patients $15(50 \%)$ were male and $15(50 \%)$ were females (table 4.1 ). Most of the patients were found in age range of 5-10 years according to frequency $16(53.3 \%)$ followed by $10(33.3 \%)$ patients in $10-15$ years and 4 (13.3\%) in 15-20 years (Table 4.2). Table 4.3 showed that the preoperational stage of cognitive development that represents the ability of young children to think, learn and express symbolically. The question based on this stage showed that the girls were more impaired than boys. Pretend play, Centration and irreversibility are the aspects in which boys were tending to show better than girls. In concrete operational stage of cognitive development which represented that child during this stage able to think more sensibly and demonstrate logically as well. Table 4.4 showed equal lag between boys and girls. In formal operational stage of cognitive development, the girls and boys were found to exhibit equal lag in cognitive abilities. Table 4.5 Shows only 2 out of 4 patients had been found meeting the criteria for the abstract thought and meta-cognition which were the aspect of this stage. 
Table 1.1 : Frequency of lag in Preoperational stage

\begin{tabular}{|c|c|c|c|c|c|}
\hline \multirow{2}{*}{$\begin{array}{c}\text { Stages } \\
\text { Preoperational }\end{array}$} & Yes & No & Yes & \multirow{2}{*}{ total } \\
\cline { 2 - 5 } & $14(46.7 \%)$ & $1(3.3 \%)$ & $15(50 \%)$ & $0(0.00 \%)$ & $30(100.0 \%)$ \\
\hline Pretend play & $13(43.3 \%)$ & $2(6.7 \%)$ & $13(43.3 \%)$ & $2(6.7 \%)$ & $30(100.0 \%)$ \\
\hline Egocentrism & $13(43.3 \%)$ & $2(6.7 \%)$ & $10(33.3 \%)$ & $5(16.7 \%)$ & $30(100.0 \%)$ \\
\hline Animism & $10(33.3 \%)$ & $5(16.7 \%)$ & $12(40.0 \%)$ & $3(10.0 \%)$ & $30(100.0 \%)$ \\
\hline Artificialism & $12(40.0 \%)$ & $3(10.0 \%)$ & $12(40.0 \%)$ & $3(10.0 \%)$ & $30(100.0 \%)$ \\
\hline Transductive reasoning & $10(33.3 \%)$ & $5(16.7 \%)$ & $12(40.0 \%)$ & $3(10.0 \%)$ & $30(100.0 \%)$ \\
\hline Centration & $10(33.3 \%)$ & $5(16.7 \%)$ & $10(33.3 \%)$ & $5(16.7 \%)$ & $30(100.0 \%)$ \\
\hline Conservation & $12(40.0 \%)$ & $3(10.0 \%)$ & $15(50 \%)$ & 0 & $30(100.0 \%)$ \\
\hline Irreversibility & $9(30.0 \%)$ & $6(20 \%)$ & $8(26.7 \%)$ & $7(23.3 \%)$ & $30(100.0 \%)$ \\
\hline Class inclusion & $9(30.0 \%)$ & $6(20 \%)$ & $6(20 \%)$ & $9(30.0 \%)$ & $30(100.0 \%)$ \\
\hline Transitive interference & & &
\end{tabular}

Table 1.2 : Frequency of lag in Concrete operational stage

\begin{tabular}{|c|c|c|c|c|c|}
\hline \multirow{2}{*}{ Concrete operational stage } & \multicolumn{2}{|c|}{ Girls } & \multicolumn{2}{|c|}{ Boys } & \multirow{2}{*}{ Total } \\
\cline { 2 - 5 } & Yes & No & Yes & No & \\
\hline Inductive reasoning & $2(6.7 \%)$ & $13(43.3 \%)$ & $3(10.0 \%)$ & $12(40.0 \%)$ & $30(100.0 \%)$ \\
\hline Deductive reasoning & $2(6.7 \%)$ & $13(43.3 \%)$ & $3(10.0 \%)$ & $12(40.0 \%)$ & $30(100.0 \%)$ \\
\hline Classification & $6(20 \%)$ & $9(30.0 \%)$ & $8(26.7 \%)$ & $7(23.3 \%)$ & $30(100.0 \%)$ \\
\hline Conservation & $10(33.3 \%)$ & $5(16.7 \%)$ & $10(33.3 \%)$ & $5(16.7 \%)$ & $30(100.0 \%)$ \\
\hline Decentering & $6(20 \%)$ & $9(30.0 \%)$ & $7(23.3 \%)$ & $8(26.7 \%)$ & $30(100.0 \%)$ \\
\hline Reversibility & $6(20 \%)$ & $9(30.0 \%)$ & $7(23.3 \%)$ & $8(26.7 \%)$ & $30(100.0 \%)$ \\
\hline Imaginary audience & $6(20 \%)$ & $9(30.0 \%)$ & $7(23.3 \%)$ & $8(26.7 \%)$ & $30(100.0 \%)$ \\
\hline Personal febale & $6(20 \%)$ & $9(30.0 \%)$ & $6(20 \%)$ & $9(30.0 \%)$ & $30(100.0 \%)$ \\
\hline Justification & $6(20 \%)$ & $9(30.0 \%)$ & $6(20 \%)$ & $9(30.0 \%)$ & $30(100.0 \%)$ \\
\hline No of time asking & $8(26.7 \%)$ & $7(23.3 \%)$ & $4(26.7 \%)$ & $11(23.3 \%)$ & $30(100.0 \%)$ \\
\hline Word choice & $4(26.7 \%)$ & $10(33.3 \%)$ & $5(16.7 \%)$ & $11(23.3 \%)$ & $30(100.0 \%)$ \\
\hline
\end{tabular}

Fig 1.3: Frequency of lag in formal-operational stage

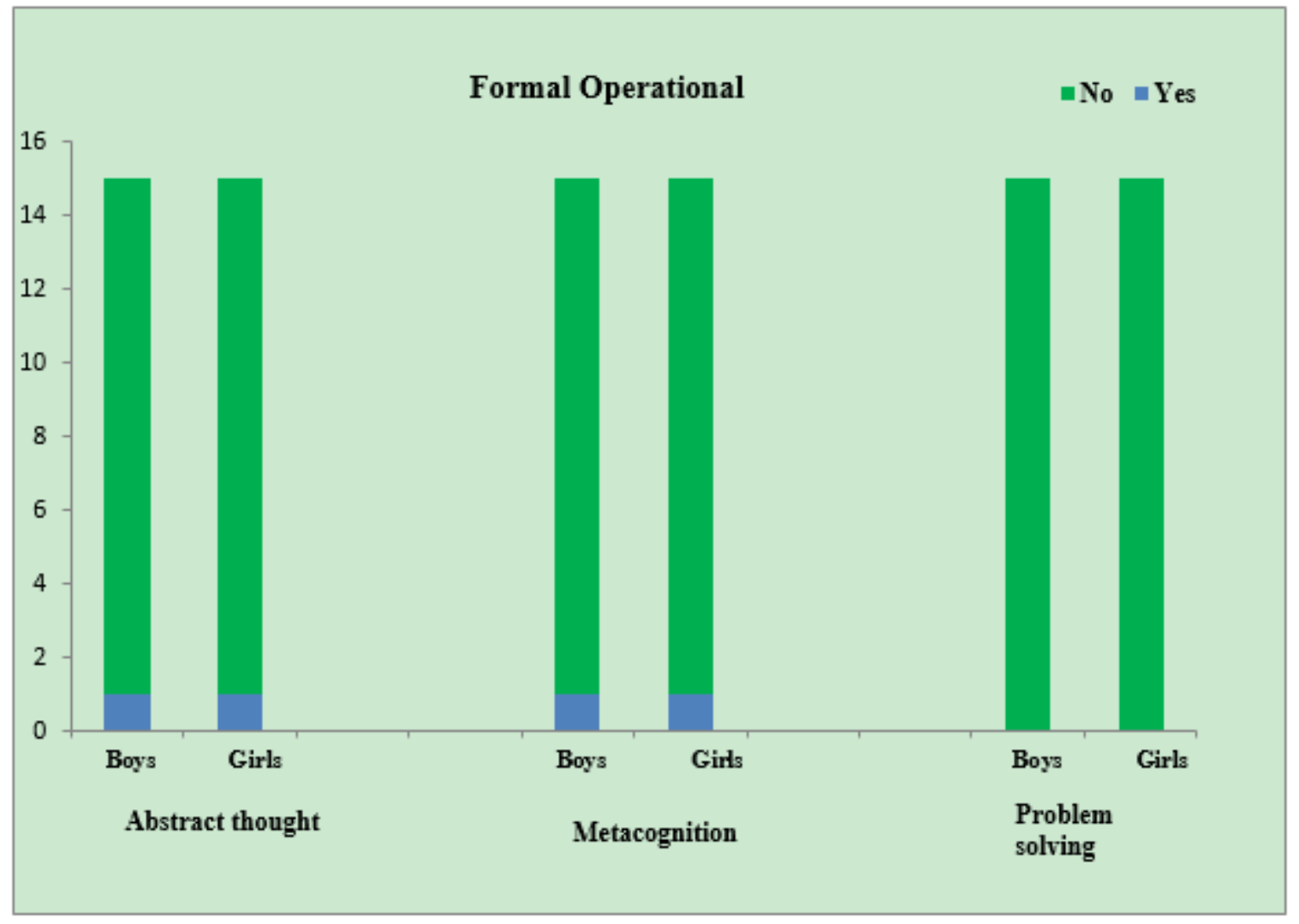




\subsubsection{Discussion}

$\mathrm{t}$ Down syndrome is an autosomal inherited disorder characterized by recognizable physical features and limitations in cognitive abilities. Cognition is a term used to describe higher mental functions associated with thinking, knowing, remembering, perception, attention span, learning and communication. This study focuses on the cognitive abilities in males and females with Down syndrome.

The present study shows that out of 30 patients with Down syndrome in which $15(50 \%)$ are males and $15(50 \%)$ are females; in pre-operational stage of cognitive development girls are more cognitively impaired than boys. In concrete-operational and formal-operational stages of cognitive development the boys and girls have been found to exhibit equal lag in cognitive abilities which are essential for doing higher mental functions by accurately and precisely.

In our research females were better in pre-operational stage .Our results resemble with the study of Tuomo et al.,(2006) who conducted the study on mental health, adaptive behavior and intellectual abilities of people with Down syndrome $(\mathrm{n}=129)$ that shows females have better cognitive abilities and speech production as compared with males. And males have more behavioral problems than females.

Brugge et al., (1994)conducted a study on group of adults with Down syndrome, 22 to 51 year old. Results showed that subgroup of adults with Down syndrome had been identified as memory impaired. This group had demonstrated a decline in performance on various cognitive tests with advancing age. These results resemble with our study because males and females showed cognitive impairments. (11).

Leanard Abbeduto, (2001) conducted research on The Linguistic And Cognitive Profile of down syndrome Comparison with Fragile X syndrome researchers concluded that individuals with down's syndrome show impairment in expression, receptive language and state of mind while individuals with fragile $\mathrm{x}$ syndrome does not show all these impairments. These results resembles with our study as it shows the cognitive impairment in individuals with Down syndrome.(9)

Our studies are reflection of the studies of Chapman (2006) Language learning in Down syndrome in their studies they have compared the speech language profile of adolescents of different origins with down syndrome 20 adults with down syndrome were compared with individuals with cognitive impairment and were marked statistically with age and nonverbal impairment, results showed that the age-related strengths in vocabulary comprehension are not limited to Down syndrome phenotype, but they are limited to certain type of vocabulary test: for both groups, performance on the Peabody Picture Vocabulary Test-3 is significantly greater than performance on the vocabulary subtest of the Test of Auditory Comprehension of Language-3, which does not differ from the syntax comprehension subtests. Vocabulary size is strength for adolescents with cognitive impairment. In comparison, defects of auditory-verbal work $\neg$ ing memory, syntax and vocabulary comprehension, and narration of picture-books them are all specific to the adolescent group with Down syndrome. The expressive language deficit disappears when a preview opportunity and picture support is given as memory which is the part of cognition is weak in individuals with Down syndrome.(7)

\subsubsection{Conclusion}

In the children with Down syndrome it is observed that there is high frequency of cognitive impairment and girls are more cognitively impaired than boys. Problem solving which is the aspect of formal operational stage is totally absent in both genders. While the tasks which require more accuracy and intelligence such as reasoning, metacognition, inductive and deductive reasoning are rarely present in both genders.

The current study has been conducted very carefully but there are some limitations \& problems of research. Which are following:

- $\quad$ Due to time limitation we are able to ascertain only 30 patients.

- $\quad$ Some care givers were not co-operative.

- Data was collected only from two institutions.

\subsection{Suggestions}

Cognition is basic and important part of our mental functions which helps us in our educational, vocational and Activities of daily livings. Our study suggested that

- $\quad$ Workshops should be arranged for the awareness of Down syndrome.

- $\quad$ Early educational and vocational programs should be introduced

- $\quad$ Data should collect from different hospitals and special educational institutions.

- $\quad$ Do more efforts on this topic with a larger sample size.

\section{References}

1. Reed KL, Zukas RR. Quick reference to occupational therapy: Pro-ed; 2001.

2. Prevention CfDCa. Occurrence of Down syndrome in the United States 2017 [Available from: https://www.cdc.gov/ncbddd/birthdefects/downsyndrome/data.html. 
3. Karen Gill M. Down Syndrom 2017 [Available from: https://www.healthline.com/health/downsyndrome\#causes.

4. Myers DG. Myers' psychology for AP: Macmillan; 2010.

5. Michelon DP. What are the cognitive abilities and skills and how to boost them 2006 [Available from: https://sharpbrains.com/blog/2006/12/18/what-are-cognitive-abilities/.

6. Diana W Schofield MLW, Caroly Pataki, . Cognitive Deficits 2016 [Available from: https://emedicine.medscape.com/article/917629-overview.

7. Chapman R. Language learning in Down syndrome: The speech and language profile compared to adolescents with cognitive impairment of unknown origin. Down Syndrome Research and Practice. 2006;10(2):61-6.

8. Määttä T, Tervo-Määttä T, Taanila A, Kaski M, Iivanainen M. Mental health, behaviour and intellectual abilities of people with Down syndrome. Down syndrome research and practice. 2006;11(1):37-43.

9. Abbeduto L, Pavetto M, Kesin E, Weissman M, Karadottir S, O’Brien A, et al. The linguistic and cognitive profile of Down syndrome: Evidence from a comparison with fragile X syndrome. Down Syndrome Research and Practice. 2001;7(1):9-15.

10. Wishart J, Manning G. Trainee teachers' attitudes to inclusive education for children with Down's syndrome. Journal of Intellectual Disability Research. 1996;40(1):56-65.

11. Brugge KL, Nichols S, Salmon D, Hill L, Delis D, Aaron L, et al. Cognitive impairment in adults with Down's syndrome Similarities to early cognitive changes in Alzheimer's disease. Neurology. 1994;44(2):232-. 